\title{
Potential energy savings by application of the novel CRIMSON aluminium casting process
}

\author{
Xiaojun Dai ${ }^{\mathrm{a}}$, Mark Jolly ${ }^{\mathbf{b}^{*}}$ \\ ${ }^{\mathrm{a}, \mathrm{b}}$ School of Mechanical Engineering, University of Birmingham, Edgbaston, Birmingham, B15 2TT, UK \\ * Corresponding author. Email: m.r.jolly@bham.ac.uk; Tel: +44(0) 121414 7355; Fax: +44(0) 1214144168
}

\begin{abstract}
Compared with its output the casting industry uses a disproportionate amount of energy as a result of the inefficient processes used. This paper presents the melting processes that are used in one of the traditional foundries and identifies the energy burdens associated with them. A comparison is then made with the novel CRIMSON process to demonstrate where energy savings can be made. An actual case or casting sample is investigated to demonstrate the advantage of energy saving in novel CRIMSON method which will help the foundry industry in reduction of energy cost and promote competitiveness in the production of high end casting components.
\end{abstract}

Key Words: energy saving, aluminium casting, melting, CRIMSON

\section{Introduction}

The metal casting industry is naturally very energy intensive. Energy consumption in foundry mainly depends on electricity gas and oil. It is estimated that the energy required in melting and heating in a typical metal casting facility is $60 \%$ to $75 \%$ of the total energy used in the facility [1].The energy efficiency of any metal casting facility depends largely on the efficiency of its melting and heat treating operations. In conjunction with the two operations, over $60 \%$ of the total process energy costs are represented in a typical casting facility [2]. Therefore, there are huge opportunities for metal casting industry to adopt the best energy solutions which will offer the great energy saving potential. To improve the energy efficiency of these operations will have an important effect on reducing the manufacturing cost and promote the competitiveness. For example, by implementing some cuttingedge technology such as the CRIMSON method in aluminium alloy casting will take advantage of such opportunities.

The CRIMSON (Constrained Rapid Induction Melting Single Shot Up-Casting) method was coinvented by researchers and engineers of University of Birmingham and a local company, - N-Tec Ltd. The aim is to reduce the energy consumption and to improve the casting quality within light-metal shape casting industry. The method's main philosophy is that foundries, using an induction furnace, need only to melt the quantity of metal required to fill a single mould in a closed crucible rather than large batches that use unnecessary energy and create more rejects. The closed crucible, then, is transferred to a station and the melted metal is push up using a computer controlled anti-gravity filling method to fill the mould. Due to a feature of rapid melting, transfer and filling in the new method, the holding time of melted metal is minimised, a drastic energy saving is achieved and in the mean time 
the possibility of hydrogen absorption and formation of surface oxide film are reduced to a great extent [3]. In this paper, the traditional melting and casting processes from one local company are investigated and they are compared with the novel method. The calculation and analysis of energy consumption are completed to see what the difference between the current melting processes and the novel method. Then, the potential energy saving for the novel method can be found. This comparison is only one of a number being carried out under the auspices of an EPRSC project whereby 4 traditional casting processes will be benchmarked for their energy usage and scrap rates.

\section{Audit the energy consumption of melting processes in traditional foundry}

Energy audit is the definition for "a thorough mapping of energy and water use, all beneficial saving possibilities, and the renewable form of energy usable possibilities of the building and the production process carried out by experts" [4]. Usually, energy used in foundry will be electricity, gas, oil and other forms. In this paper, we mainly focus on the energy consumption of melting processes, other energy consumption issues will be investigated later in our research project. The energy burden of the melting and holding processes is a large part of the total energy used in the foundry. Figure 1 gives an estimate of the process-specific energy profile of the metal casting industry based on tacit energy and it was calculated by converting delivered energy data, obtained from published energy reports, to tacit energy (Tacit energy is a term used to describe an energy value that equals the combination of onsite energy consumption, the process energy required to produce and transmit/transport the energy source, and feedstock energy). Melting and holding stands out above all other process areas with an estimated 72 percent of the metal casting industry tacit energy consumption [5].

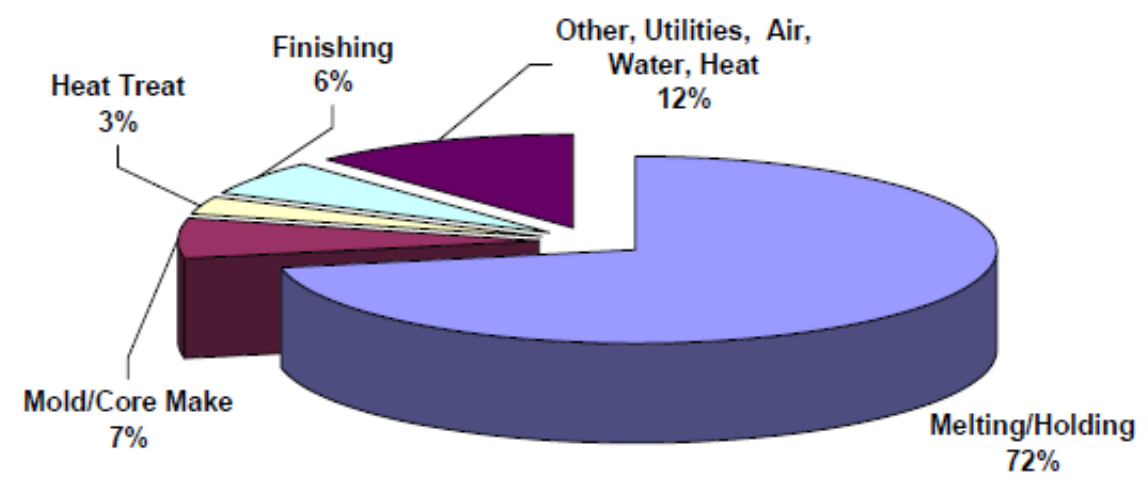

Figure 1. Typical metal casting tacit energy profile by process

In UK, most of the foundry use electricity, gas and oil as the fuel in the melting processes. Traditionally, the majority of foundries melt the alloys to be cast first and then hold the melted alloys in a furnace for long time, sometimes for the duration a full shift. The purpose of holding the molten alloys is to pour the moulds in batches. This process planning method is convenient and flexible for the foundry personnel to operate in normal circumstances. However, for every hour the metal is held energy is unnecessarily. Theoretically, the quantity of energy required for melting one tonne of aluminium to a superheat of $100{ }^{\circ} \mathrm{C}$ is calculated to be $1.1 \mathrm{GJ} /$ tonne $(\sim 306 \mathrm{KWh} /$ tonne $)$ [3]. Figure 2 
[3] shows the flow chart of foundry process where the energy loss at each stage is indicated. In the worst cases for each stage, the figure of the final energy cost could be $182 \mathrm{GJ} /$ tonne ( $50.6 \mathrm{MWh} /$ tonne) [3]. In the current research project, a specific casting has been identified and the energy consumption is audited by comparing the traditional melting process and the new process.



Figure 2. Flow chart of aluminium foundry processes with estimated energy losses at each stage.

(The cycle is treated as a closed loop and discounts the embedded energy within the casting ingot supplied by the primary industry)

Traditional foundry ingot is supplied in what are called "pigs" and are roughly trapezoidal in cross section (Figure 3a). For the new process a circular cross section direct chill (DC) cast billets (Figure 3b) would be required in order obtain the best efficiency of heating with the RF induction coil. The latter route has an added benefit in also being a metal of higher quality. Traditionally produced foundry ingot is cast in a turbulent fashion which inherently produces poor quality metal to start with thus starting with DC cast billet is an immediate advantage. It is not possible at this stage to purchase small volumes of DC cast foundry alloy billet. For this project it was necessary to re-cast the traditional ingot into billets after treating the melt to reduce the oxide content. In order to make a comparison of the traditional processes with the new process route the initial casting of the stock has been left out of the energy audit for both routes. In other words the starting point has been chosen as the metal in solid billet or ingot form required by the process. This can be justified by specifying that if the new process were adopted by the industry it would only be feasible if the starting stock was foundry alloy in billet form of the correct diameter. 


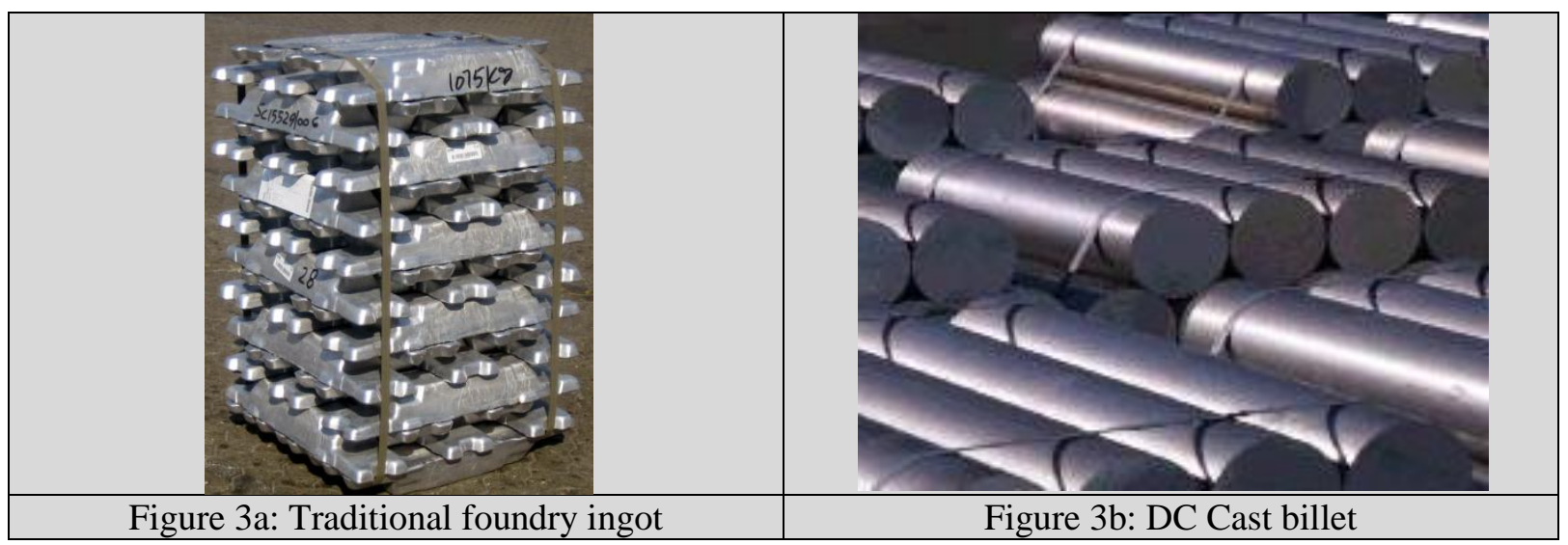

\section{Case investigation - Grainger \& Worrall Co. Ltd.}

One of the foundries for producing high end casting components in Grainger \& Worrall (G\&W) Ltd. is currently using one type of melting furnace (Figure 4) with combining melting process where the primary melting area can be called a melting area and gas is used to melt aluminium ingot, then the melted aluminium alloy flowing along an inclined channel to a refining area where an electric resistance furnace is used. The refined liquid aluminium alloy is held in the electric resistance furnace. "Pouring" is carried out using an electromagnetic pump to pump the liquid metal to the mould. This is called the "Cosworth" process. In this foundry, there are two furnaces using this kind of combining melting processes for producing two types of aluminium alloys-A354 and A357. The capacity of both furnaces is 4 tonne. The holding time for each furnace is up to 4-5 days. The overheating temperature of A354 aluminium alloy is $760{ }^{\circ} \mathrm{C}$. The pouring temperature of the melted $\mathrm{Al}$ alloy is $700{ }^{\circ} \mathrm{C}$.

$\mathrm{G} \& \mathrm{~W}$ is currently using traditional sand casting processes to produce normal casting components and the Cosworth casting process is especially selected to produce high quality components. A "Test bar" mould has been selected to use novel method to examine its energy consumption. The design of the "Test bar" with a runner system is shown in Figure 5 which has a profile of $530 \mathrm{~mm}$ length x $390 \mathrm{~mm}$ width $\mathrm{x} 100 \mathrm{~mm}$ height with a weight of $4 \mathrm{~kg}$. [6] 


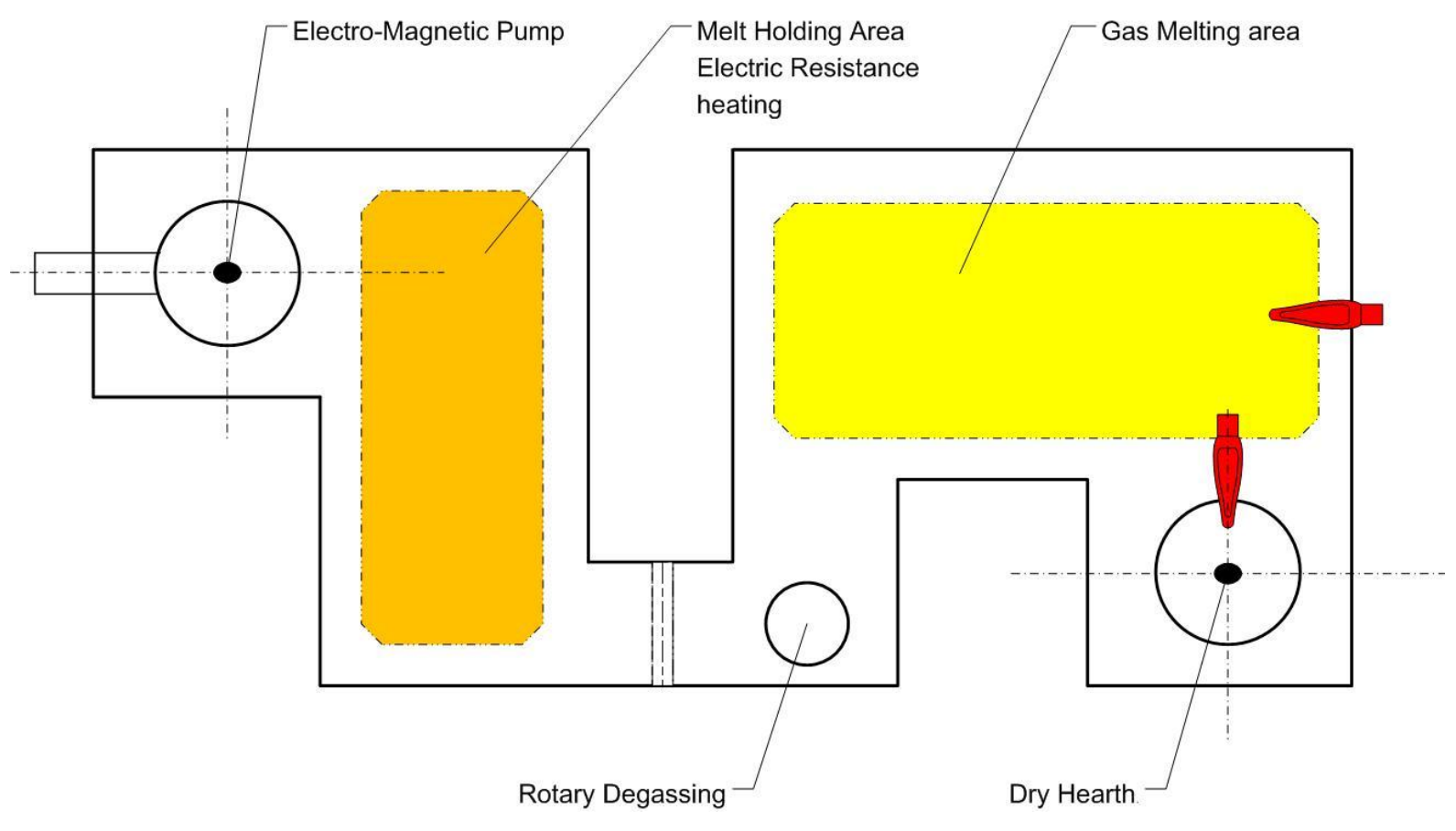

Figure 4.The schematic plan of the furnace in G\&W Ltd.



Figure 5. The structure of the "Test bar" with runner system [6].

-Calculation of energy consumption of melting process:

Without considering the chemical reaction, slag formation and other heat losses, the theoretical calculation of energy for heating A354 aluminium alloy to $760{ }^{\circ} \mathrm{C}$ is as follows [7]: 


$$
Q=m C_{m 1}\left(T_{m}-T_{1}\right)+Q_{f}+m C_{m 2}\left(T_{2}-T_{m}\right)
$$

Here, $\quad Q$ is the heat that is needed to heat and melt the $\mathrm{Al}$ alloys;

$m$ is the mass of the $\mathrm{Al}$ alloy;

$C_{m 1}$ is the specific heat for solid A354 Al alloys, $1.07 \mathrm{~kJ} \mathrm{~kg}^{-1} \cdot{ }^{\circ} \mathrm{C}^{-1}[7]$;

$C_{m 2}$ is the specific heat for liquid A354 Al alloys, $1.05 \mathrm{~kJ} \cdot \mathrm{kg}^{-1} \cdot{ }^{\circ} \mathrm{C}^{-1}[7]$;

$T_{m}$ is the melting temperature of $\mathrm{A} 354 \mathrm{Al}$ alloys, $596^{\circ} \mathrm{C}[8]$;

$T_{1}$ is the environment temperature, $20^{\circ} \mathrm{C}$;

$\mathrm{T}_{2}$ is the superheat temperature, $760{ }^{\circ} \mathrm{C}$;

$Q_{f}$ is the heat of fusion, $389 \mathrm{~kJ} \mathrm{~kg}^{-1} \cdot{ }^{\circ} \mathrm{C}^{-1}[8]$;

a) Calculation of the gas consumption;

In this case, the gas is used to heat the $\mathrm{Al}$ alloys to its melting point $596{ }^{\circ} \mathrm{C}$ and melt the alloys.

Therefore, the heat $Q_{1}$ for heating and melting the $\mathrm{Al}$ alloys can be calculated as:

$$
\begin{aligned}
& Q_{1}=m C_{m 1}\left(T_{m}-T_{1}\right)+Q_{f} \\
& Q_{1}=1.07(596-20)+389=1005 \mathrm{~kJ} \cdot \mathrm{kg}^{-1}
\end{aligned}
$$

b) Calculation of the electricity consumption;

In this case, the electricity is used to overheat the melted $\mathrm{Al}$ alloys to $760{ }^{\circ} \mathrm{C}$.

Therefore, the heat $Q_{2}$ for overheating the $\mathrm{Al}$ alloys can be calculated as:

$$
Q_{2}=m C_{m 2}\left(T_{2}-T_{m}\right)
$$

c) Total energy consumption

$$
Q_{2}=1.05(760-596)=172 \mathrm{~kJ} \cdot \mathrm{kg}^{-1}
$$

Combining $Q_{1}$ and $Q_{2}$, the total theoretical energy consumption $Q_{t 1}$ for melting A354 Al alloys to $760{ }^{\circ} \mathrm{C}$ is:

$$
Q_{t 1}=Q_{1}+Q_{2}=1005+172=1177 \mathrm{~kJ} \cdot \mathrm{kg}^{-1}=327 \mathrm{kWh} \cdot \text { tonne } \mathrm{e}^{-1}
$$

During the heating and melting processes of $\mathrm{Al}$ alloys, the actual energy consumption in a furnace is higher than the value of theoretical calculation due to the heat losses from conduction, radiation, convection, drossing and oxidation etc. It is estimated [9] that the thermal efficiency is 7 19\% for a crucible furnace using natural gas, $59 \sim 76 \%$ for an induction furnace using electricity. (The average values of the thermal efficiency are selected in this case: $\eta_{1}=13 \%$ for the gas; $\eta_{2}=67.5 \%$ for electricity.)

The energy consumption at G\&W where the Cosworth process is applied was investigated where both gas and electricity are included and the usages are recorded in Table 1. It should be pointed out that 
power measurement may link with the day or night rate. Here, only the energy consumption ( $\mathrm{kJ} . \mathrm{kg}^{-1}$ or MJ. $\mathrm{kg}^{-1}$ ) is measured and the cost which linking with the rate is not considered in this measurement.

\begin{tabular}{|c|c|c|}
\hline Energy type & Energy consumption & Energy density by mass (MJ.kg $\left.{ }^{-1}\right)$ \\
\hline LPG (propane) [10] & $\left(0.7 \mathrm{~m}^{3}\right.$. tonne $\left.^{-1}\right) 65.31 \mathrm{~kJ} . \mathrm{kg}^{-1}$ & 49.6 \\
\hline Electricity & $\left(2800 \mathrm{kWh} \cdot\right.$ tonne $\left.\mathrm{e}^{-1}\right) 10.08 \mathrm{MJ} \cdot \mathrm{kg}^{-1}$ & -------- \\
\hline
\end{tabular}

Table 1. Actual consumption of gas and electricity in G\&W Ltd where the Cosworth process is applied.

From Table 1, the total actual energy consumption $Q_{t 2}$ for melting A354 Al alloys in G\&W can be calculated as follows:

$$
Q_{t 2}=0.7 \times 49.6 \times \frac{10^{6}}{3600}+2800=9644+2800=12444 \mathrm{kWh} . \text { tonne }^{-1}=44.80 \mathrm{MJ} . \mathrm{kg}^{-1}
$$

The thermal efficiency of using the LPG for melting the alloys:

$$
\eta_{1}^{\prime}=1005 \div 9644=10.4 \%
$$

The thermal efficiency of using the electricity for holding the melt:

$$
\eta_{2}^{\prime}=172 \div 2800=6.14 \%
$$

\section{Audit energy consumption of new process}

\subsection{The novel casting facility}

The structure of the novel casting process facility is indicated in Figure 6,

Where the Up-caster's features are as follows:

a. High power Induction furnace $(275 \mathrm{KW})$ : it is used to quickly heat and melt the metal to the required pouring temperature. Usually each time, a billet of the required size and calculated amount of metal is put in, also the composition of the billet should be consistent with the casting component that will be poured and produced;

b. Up-caster: when the crucible with the melted metal inside is ready, it is moved and cramped in the right position in Up-caster and a mould is located on the top of pouring position, a piston in the Up-caster will raise and push the melted metal in the crucible into the mould;

c. Computer-controlled operation table of the Up-caster: the movement of the piston in Upcaster is automatically controlled by the pre-programmed computer program;

d. Mould transfer stop: after pouring, cooling down and solidification, the mould can be moved to the transfer stop, waiting for lifting and cleaning; 

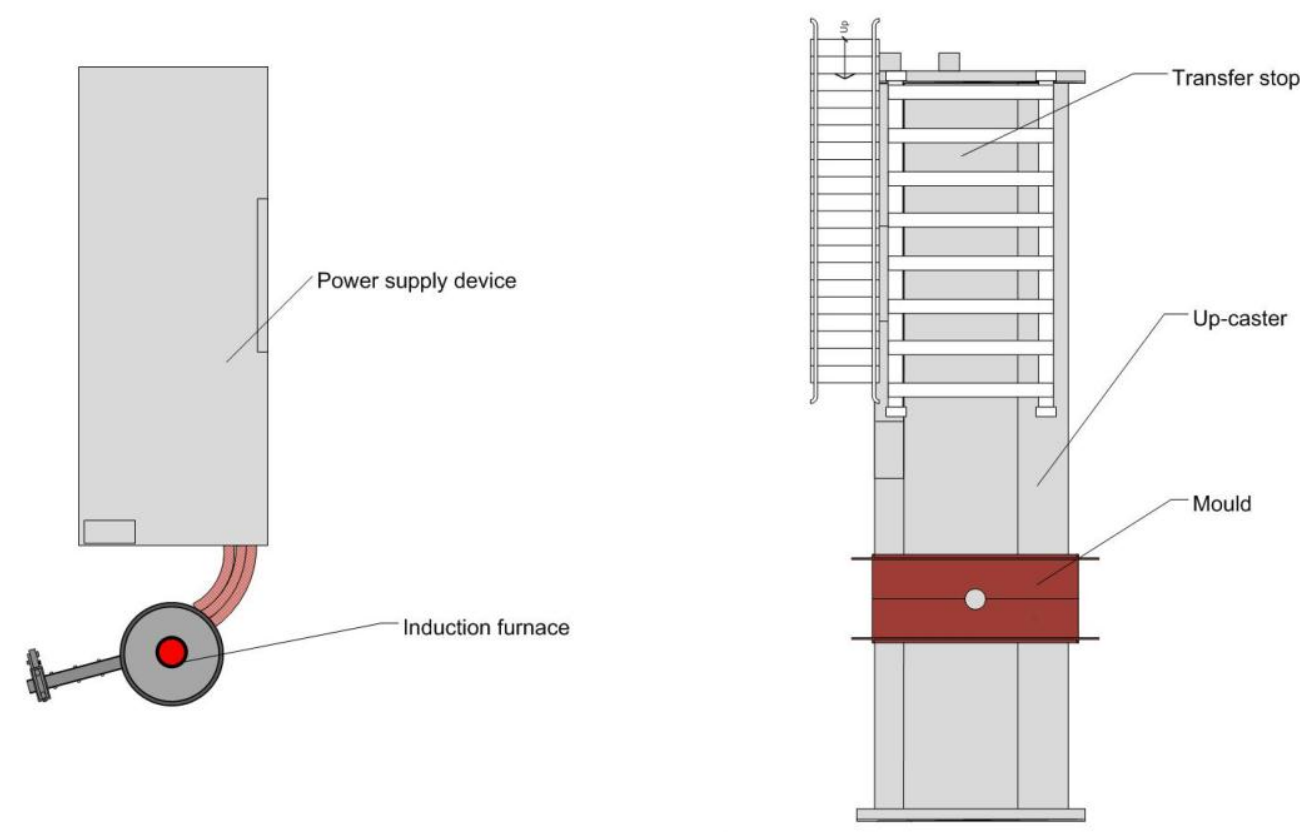

Computer controlled board

Figure 6. The schematic plan of the new casting process facility

\subsection{Calculation of energy consumption of novel casting method}

Experimental parameters for casting the "Test bar" mould in the new casting facility are given in Table 2:

\begin{tabular}{|l|l|l|}
\hline Experiment parameter & \multicolumn{1}{|c|}{ Value } & Note \\
\hline Weight of metal charge & $4 \mathrm{~kg}$ & \\
\hline Melt temperature & $729^{\circ} \mathrm{C}$ & Using thermal couple \\
\hline Melting time & 2 minutes & \\
\hline Injection time of Up-caster & 10 Seconds & \\
\hline Holding time & 20 Seconds & \\
\hline Solidification time for & 28 Seconds & \\
\hline $\begin{array}{l}\text { Measured energy consumption } \\
\text { melting the charge }\end{array}$ & \\
\hline
\end{tabular}

Table 2. Experimental parameters for the "Test bar" in the new casting process facility

The theoretical energy consumption $Q_{t 3}$ for heating the A354 alloy to $729^{\circ} \mathrm{C}$ can be calculated using equation 2.1 .

$$
Q_{t 3}=m C_{m 1}\left(T_{m}-T_{1}\right)+Q_{f}+m C_{m 2}\left(T_{2}-T_{m}\right)=1145 \mathrm{~kJ} \cdot \mathrm{kg}^{-1}=318 \mathrm{kWh} \cdot \text { tonne }^{-1}
$$


The energy consumption measured during the melting was 1.98 GJ.tonne- $^{1}$ ( $550 \mathrm{kWh}$. tonne $^{-1}$ ) (Table 2). The thermal efficiency of the induction furnace can be calculated from these two figures and is given below:

$$
\eta_{c}=\frac{1145}{1980} \times 100 \%=57.8 \%
$$

\section{Comparison and discussion of energy consumption between traditional foundry and the new casting method}

The normal thermal efficiency (average $\eta_{1}=13 \%$ ) of crucible furnace for melting $\mathrm{Al}$ alloys using gas and the thermal efficiency $\left(\eta_{1}^{\prime}=10.4 \%\right)$ of furnace using LPG at G\&W are in the normal range $7 \sim 19 \%$ although it is a bit lower than the expected average value $(13 \%)$. The difference in the thermal efficiency $\left(\eta_{2}^{\prime}=6.14 \%\right)$ of holding furnace using electricity at G\&W with the normal thermal efficiency $\left(\eta_{2}=59 \sim 76 \%\right.$ ) of an induction furnace was a much larger than expected. This suggests that there are great savings to be made in identifying why these poor efficiencies exist. If it were possible to replace the large holding and melting furnaces at G\&W by single shot melting then melting efficiencies could be improved by upwards $40 \%$. Thus reducing production cost.

During the "Test bar" experiment using the new up-casting facility, the thermal efficiency $\eta_{c}$ was calculated as $57.8 \%$ which is close to the normal thermal efficiency of an industrial induction furnace $\left(\eta_{2}=59 \sim 76 \%\right)$. The reason for the heat loss in up-casting process facility can be attributed to radiation, conduction and convection between the melt and the surrounded environment. When melting the same weight of the Al alloys, G\&W used 22.6 times more energy than the new casting facility. It is estimated that $42.8 \mathrm{GJ}^{\text {.tonne }} \mathrm{e}^{-1}$ (11.9 MWh.tonne $\mathrm{M}^{-1}$ ) can be saved for producing every tonne of A354 casting alloys when using the new process.

Further reasons for recommending choosing the new casting method and as opposed to using crucible furnace in $\mathrm{G} \& \mathrm{~W}$ are: a crucible furnace is less expensive melting method for melting $\mathrm{Al}$ alloys which is popular in foundry due to its easy for tapping and charging different alloys. However, the thermal efficiency of the crucible furnace is far lower (7 19\%) than the new casting method (57.8\%), and the temperature of the melted alloys is difficult to control. It has been proved in the case of G\&W where the thermal efficiency is only $10.4 \%$. Furthermore, the new up-casting method uses a quick pouring method as soon as the alloy is heated to the casting temperature, avoiding using holding furnace or needing holding time, reduces the potential energy waste. In the mean time, due to the rapid melting and filling processes, the possibility of producing the oxide film on the surface of the melted Al alloys and the potential time for hydrogen ingress are drastically reduced. Therefore, the quality of the casting can be assured. 


\section{Conclusions and future work}

Comparing the thermal efficiency and energy consumption of melting processes between the traditional foundry and the novel melting method, both the theoretical calculation and the experiment results give the following conclusion: the new method is an advanced method for saving energy in the casting industry. If the traditional foundries in the study could use the novel melting method instead of their usual method, the estimated energy savings could be of the order of 43 GJ.tonne- ${ }^{1}$ (11.9 MWh.tonne $\mathrm{M}^{-1}$ ) can for A354 alloy. This would drastically reduce their production cost by about $£ 904$ pounds.tonne $\mathrm{e}^{-1}\left(7.6 \mathrm{p} . \mathrm{kWh}^{-1}\right)$. This will become more important in the intensively competitive market of the future.

The other aspects of the energy consumption for the whole foundry will be further considered in the research project which is not only consider the melting process, but also include casting and other relevant processes.

\section{Acknowledgement}

This research project is funded and sponsored by the Engineering and Physical Sciences Research Council (EPSRC) of the UK under the grant of EP/G060096/1. Many thank to the N-Tec Ltd. and University of Birmingham for supplying the experiment equipment. Especially, acknowledgement will be given to the Grainger \& Worrall Ltd. and Mr. Martin Wood for providing the data of their current melting process and the energy consumption. 


\section{References}

[1] V.J. Saha, Energy Efficiency Improvement in Melting Furnaces, Report, World Foundrymen Organisation, 2010.

[2] R. Eppich, R.D. Naranjo., Implementation of Metal Casting Best Practices, Report of U.S. Department of Energy, 2007.

[3] M. Jolly, Energy Saving in the Foundry Industry by Using the "CRIMSON" Single Shot UPCasting Process, 2010 TMS Annual Meeting \& Exhibition, Febuary 14-18, 2010, Seattle, WA.

[4] M. Seppanen, Foundrybench-D3 Description of common energy analysis methods, tools and reporting templates appropriate for the purpose of the project, Report, 2009.

[5] J.F.Schifo, J.T. Radia., Theoretical/Best Practice Energy Use in Metalcasting Operations, KERAMIDA Environmental, Inc. Indianapolis, May 2004.

[6] J. C. Geelin, M. Lovis \& M.R. Jolly, SIMULATION OF TENSILE TEST BARS: DOES THE FILLING METHOD MATTER?, Symposium on Simulation of Aluminum Shape Casting Processing, TMS2006 March 2006, Warrendale, PA, Eds Q. Wang, M.J.M Krane and P.D Le.

[7] C. Schmitz, Handbook of aluminium recycling: Fundamentals, Mechanical Preparation, Metallurgical Processing, Plant Design, Vulkan-Verlag GmbH, Germany, 2006.

[8] MatWed MATERIALS PROPERTY DATA, http://www.matweb.com/search/MaterialGroupSearch.aspx

[9] BSC, Incorporated, Advanced Melting Technologies: Energy Saving Concepts and Opportunities for the Metal Casting Industry, Report, U.S. Department of Energy, 2005.

[10]-Wikipedia-Energy density:

http://webcache.googleusercontent.com/search?q=cache:COLNRICHJmUJ:en.wikipedia.org/wiki/Ene rgy density $+\mathrm{lpg}+$ density \&cd=2\&hl=en\&ct=clnk\&gl=uk\&client=firefox-a 